\title{
TITIK IMPAS DAN TREN USAHA SUSU KAMBING PERANAKAN ETAWA (STUDI KASUS DI PETERNAKAN AS-SALAM KELURAHAN SIRNAGALIH KECAMATAN INDIHIANG KOTA TASIKMALAYA)
}

\section{The Break Even Point and Trend of an Etawa's Goat Milk Business (Case Study in As-Salam Farm Sirnagalih Village, Indihiang District, Tasikmalaya City)}

\author{
Ane Novianty1), Sri Dwi Rahayu Umba Ginawangsasih2) \\ 1) Fakultas Pertanian, Universitas Galuh \\ 2) Dinas Pertanian Kabupaten Garut \\ Email: noviantyane29@gmail.com
}

\begin{abstract}
ABSTRAK
Penelitian dilaksanakan dengan tujuan untuk mengetahui titik impas dan tren penjualan usaha susu kambing peranakan etawa di Peternakan As-Salam, Kota Tasikmalaya. Sasaran penelitian adalah pemilik peternakan As-Salam yang menjalankan usaha susu kambing. Titik impas dianalisis menggunakan titik impas volume produksi dan harga jual, sedangkan tren penjualan dianalisis menggunakan analisis tren berdasarkan histori data penjualan 3 tahun terakhir Hasil penelitian menunjukkan titik impas volume produksi 205,8 liter per bulan dan titik impas harga sebesar Rp 32.565,96. Perubahan angka proyeksi penjualan setiap bulannya terhitung kecil dan cenderung meningkat, sehingga dapat dikatakan penjualan susu kambing di peternakan As-Salam memiliki prospek yang baik untuk dikembangkan.
\end{abstract}

Kata kunci: Susu Kambing Etawa, titik impas, tren

\section{ABSTRACT}

This research aims to know the break even point and trend of sales etawa's goat milk in AsSalam Farm, Tasikmalaya City. Object of the research is owner of As-Salam Farm whom exist on etawa's goat milk business. Break even point (BEP) analyze used BEP volume of production and BEP price of the product, whereas trend of sales analyze with trend analysis with timeseries data from last three years. The research result show the BEP volume of production 205,8 liters per month and BEP of prices $R p$ 32.565,96. Change of sales 
projection every month as small and tended to increase, it can said the sale of milk in AsSalam Farm has a good prospect to develop.

Key words: Etawa's goat milk, break even point, trend

\section{PENDAHULUAN}

Di banyak negara berkembang ternak kambing telah dijadikan sebagai komoditas strategis sebagai instrumen pengentasan kemiskinan (proverty alleviation) oleh kelembagaan internasional (Sodiq, 2010). Salah satu bangsa kambing yang tersebar di Indonesia yaitu kambing Peranakan Etawa (PE).

Kota Tasikmalaya merupakan salah satu daerah yang sedang mengembangkan dan memprioritaskan kambing PE untuk menjadi komoditas unggulan. Pengembangan usaha ternak kambing PE di Kota Tasikmalaya memiliki potensi yang tinggi karena didukung iklim yang sesuai dan kedekatan dengan konsumen potensial.

Melihat banyaknya kelebihan dari beternak kambing PE, seharusnya dapat menjadi peluang strategis bagi peternak untuk memulai ternak kambing PE. Namun pada kenyataannya, dari beberapa kelompok ternak kambing PE yang ada di Kota Tasikmalaya hanya tersisa satu kelompok yang konsisten dalam menjalankan usaha ternaknya. Rischkowsky (2017) menuliskan hasil kajian bahwa usaha ternak kambing di Ethiopia menunjukkan tingkat penghasilan peternak kurang memadai, meski harga pasar tinggi, dan kerap usaha peternak tiba-tiba berhenti. Penelitian ini bertujuan untuk mengetahui titik impas volume produksi dan titik impas harga serta tren penjualan susu kambing Peranakan Etawa di Peternakan As-Salam.

\section{METODOLOGI}

\section{Lokasi dan Waktu Penelitian}

Penelitian ini dilaksanakan di Peternakan As-Salam, Kelurahan Sirnagalih, Kecamatan Indihiang, Kota Tasikmalaya pada bulan Januari 2019.

\section{Metode Analisis}

Penelitian dilakukan dengan metode studi kasus, yaitu penelitian tentang status subjek penelitian yang berkenaan dengan suatu fase spesifik atau khas dari keseluruhan personalitas (Nazir, 2003). Data yang digunakan dalam penelitian ini terdiri atas data primer dan sekunder. Pemilik Peternakan As-Salam dijadikan responden tunggal untuk memberikan kebutuhan informasi terkait data. 
Analisis titik impas adalah suatu teknik yang mempelajari hubungan antara biaya tetap, biaya variabel, keuntungan dan volume produksi (Karjono, 2017). Analisis titik impas dalam penelitian ini menggunakan persamaan Soekartawi (2006) dalam Asnidar dan Asrida (2017) sebagai berikut :

$$
\begin{gathered}
\text { BEP produksi }(\text { liter })=\frac{\text { Total Biaya }(R p)}{\text { Harga Jual } \frac{(R p)}{(\text { liter })}} \\
\text { BEP Harga } \frac{(R p)}{(\text { liter })}=\frac{\text { Total Biaya }(R p)}{\text { Produksi }(\text { liter })}
\end{gathered}
$$

Kriteria BEP produksi adalah sebagai berikut :

a. Jika BEP produksi < jumlah produksi, maka usaha berada pada posisi menguntungkan.

b. Jika BEP produksi = jumlah produksi, maka usaha berada pada posisi titik impas atau tidak laba/tidak rugi.

c. Jika BEP produksi > jumlah produksi, maka usaha berada pada posisi yang tidak menguntungkan.

Kriteria BEP harga adalah sebagai berikut :

a. Jika BEP harga < harga jual, maka usaha berada pada posisi yang menguntungkan.

b. Jika BEP harga = harga jual, maka usaha berada pada posisi titik impas atau tidak laba/tidak rugi.

c. Jika BEP harga > harga jual, maka usaha berada pada posisi yang tidak menguntungkan.

\section{Analisis Trend}

Metode analisis trend merupakam model peramalan yang bersifat objektif (kuantitatif) (Najmudin, 2012). Trend dapat dipergunakan untuk meramalkan kondisi di masa mendatang, maupun untuk memprediksi data pada suatu kurun waktu tertentu. Metode yang digunakan untuk memodelkan trend pada penelitian ini adalah model kuadrat (Quadratic Model).

\section{HASIL DAN PEMBAHASAN}

\section{Gambaran Umum Peternakan As-Salam}

Saat ini Peternakan As-Salam mengusahakan kambing etawa dengan jumlah 60 ekor kambing yang terdiri dari 35 ekor betina, 15 ekor jantan, dan 10 ekor anakan. Susu kambing yang di produksi rata-rata 10 liter per hari dan 
dikemas dalam kemasan botol ukuran $200 \mathrm{ml}$ dengan harga jual Rp 8.000 per botol atau Rp 40.000 per liter.

\section{Break Even Point}

Analisis titik impas bisa digunakan jika dapat dibedakan menjadi biaya tetap dan biaya variabel. Biaya tetap yang dikeluarkan oleh usaha susu kambing di Peternakan As-Salam sebesar Rp 4.555.448 atau 45,11 persen dari biaya total. Biaya variabel yang digunakan oleh Peternakan As-Salam sebesar Rp 5.540.000 atau 54,85 persen dari biaya total. Biaya variabel terbesar adalah biaya pakan ternak sebesar Rp3.410.000 atau 33,77 persen dari biaya total. Rincian biaya selanjutnya dapat dilihat pada Tabel 1.

Tabel 1 menunjukkan bahwa biaya total sebesar Rp 10.095.448. Jumlah produk yang dihasilkan oleh Peternakan As-Salam sebanyak 310 liter dengan harga jual Rp 40.000,00 per liter; sehingga penerimaan yang diperoleh sebesar Rp 12.400.000 dan pendapatan sebesar Rp 2.304.552.

Tabel 1. Analisis Titik Impas Usaha Susu Kambing di Peternakan As-Salam

\begin{tabular}{clrr}
\hline No & \multicolumn{1}{c}{ Uraian } & Jumlah & Persentase (\%) \\
\hline I & Biaya Tetap Total (TFC) (Rp) & 4.555 .448 & 45,11 \\
& Penyusutan (Rp) & 518.866 & 5,13 \\
& Gaji karyawan tetap (4 orang) (Rp) & 4.000 .000 & 39,62 \\
& Pajak bangunan kandang (Rp) & 36.582 & 0,36 \\
II & Biaya Variabel Total (TVC) (Rp) & 5.540 .000 & 54,85 \\
& Kemasan Botol & 495.000 & 4,90 \\
& Transportasi pemasaran & 200.000 & 1,98 \\
& Pakan & 3.410 .000 & 33,77 \\
& Obat-obatan & 435.000 & 4,30 \\
& Upah tenaga kerja langsung (2 orang) & 1.000 .000 & 9,90 \\
III & Biaya Total (TC) (Rp) & 10.095 .448 & 100 \\
IV & Penerimaan (Rp) & 12.400 .000 & \\
V & Jumlah Produksi (liter) & 310 & \\
VI & Pendapatan (Rp) & 2.304 .552 & \\
VII & BEP volume produksi (liter) & 205,8 & \\
VIII & BEP harga jual produk (Rp/liter) & $32.565,96$ & \\
\hline
\end{tabular}

Sumber : Analisis Data Primer, 2019

Analisis titik impas dilakukan untuk mengetahui batas nilai produk atau volume produksi usaha mencapai titik impas (tidak untung tidak rugi) (Dewi dkk, 2017). Jika BEP volume produksi lebih besar dari produksi, maka usaha tersebut dinyatakan rugi, dan jika BEP volume produksi lebih kecil dari produksi, maka usaha tersebut dinyatakan untung. Demikian pula untuk BEP harga (Karjono, 2017). 
Tabel 1 menunjukkan bahwa BEP produksi (205,8 liter) lebih kecil daripada volume produksi faktual (310 liter), sehingga dapat disimpulkan bahwa usaha susu kambing pada Peternakan As-Salam menguntungkan. BEP harga (Rp 32.565,96/liter) lebih kecil dari pada harga faktual (Rp 40.000/liter), sehingga dapat disimpulkan bahwa usaha susu kambing pada Peternakan As-Salam menguntungkan.

\section{Analisis Trend}

Data yang digunakan dalam analisis trend adalah data berkala (timeseries) selama 36 bulan yaitu dari bulan Januari 2016 sampai dengan Desember 2018. Data tersebut merupakan data penjualan susu kambing etawa dari Peternakan AsSalam yang diakumulasikan. Peramalan tersebut dilakukan untuk 24 bulan kedepan yaitu periode Januari 2019 sampai dengan Desember 2020.

Tabel 2. Hasil Proyeksi Tren Penjualan Susu Kambing Peranakan Etawa di Peternakan As-Salam Periode Januari 2019 - Desember 2020

\begin{tabular}{lrrrrr}
\hline \multirow{2}{*}{ Bulan } & \multicolumn{3}{c}{ Data riil } & \multicolumn{2}{c}{ Peramalan } \\
\cline { 2 - 6 } & $\mathbf{2 0 1 6}$ & $\mathbf{2 0 1 7}$ & $\mathbf{2 0 1 8}$ & $\mathbf{2 0 1 9}$ & $\mathbf{2 0 2 0}$ \\
\hline Januari & 120 & 240 & 290 & 327,255 & 358,428 \\
Februari & 120 & 240 & 290 & 330,812 & 359,892 \\
Maret & 120 & 240 & 290 & 334,195 & 361,181 \\
April & 110 & 240 & 300 & 337,404 & 362,296 \\
Mei & 115 & 240 & 300 & 340,438 & 363,236 \\
Juni & 115 & 230 & 300 & 343,297 & 364,001 \\
Juli & 115 & 235 & 300 & 345,982 & 364,593 \\
Agustus & 115 & 235 & 310 & 348,493 & 365,009 \\
September & 125 & 245 & 310 & 350,829 & 365,252 \\
Oktober & 125 & 245 & 310 & 352,990 & 365,319 \\
Nopember & 130 & 245 & 310 & 354,977 & 365,213 \\
Desember & 130 & 245 & 310 & 356,790 & 364,932 \\
\hline Sumber: Analisis Data Primer $(2019)$ & & & &
\end{tabular}

Berdasarkan hasil proyeksi tren penjualan pada Tabel 2, penjualan susu kambing peranakan etawa di Peternakan As-Salam mengalami kenaikan sampai dengan bulan Oktober 2020, namun kemudian menurun secara bertahap sampai Desember 2020. Perubahan angka proyeksi penjualan setiap bulannya terhitung kecil dan cenderung menaik, sehingga dapat dikatakan penjualan susu kambing peranakan etawa di peternakan As-Salam memiliki prospek yang baik untuk dikembangkan.

Logika kenaikan angka penjualan setiap bulannya dapat diilustrasikan sebagai berikut : Setiap 8 bulan sekali kambing etawa akan melahirkan satu hingga dua ekor kambing, sehingga jumlah kambing yang dimiliki oleh peternak akan semakin banyak. Hal ini dapat memengaruhi jumlah kambing yang dapat diperah 
dan jumlah susu yang dapat dihasilkan, sehingga produksi cenderung naik setiap tahunnya. Sedangkan penurunan angka penjualan ini dapat disebabkan oleh beberapa faktor, beberapa diantaranya yaitu : a) tingkat kematian indukan, b) pengaruh masa birahi dan kebuntingan yang menyebabkan produktivitas menurun, c) umur kambing, semakin tua semakin sedikit menghasilkan susu.

\section{KESIMPULAN DAN REKOMENDASI KEBIJAKAN}

a. Titik impas volume produksi sebesar 205,8 liter, dan titik impas harga jual produk sebesar Rp 32.565,96.

b. Tren penjualan susu kambing peranakan etawa di Peternakan As-Salam cenderung meningkat selama 2 tahun kedepan.

\section{DAFTAR PUSTAKA}

Asnidar dan Asrida. 2017. Analisis Kelayakan Usaha Home Industry Kerupuk Opak di Desa Paloh Meunasah Dayah Kecamatan Muara Satu Kabupaten Aceh Utara. Jurnal S. Pertanian Vol. 1 (1) : 39-47.

Dewi, N.P.H., Satriawan, I.K. dan Wrasiati, L.P. 2017. Analisis Nilai Tambah Pengolahan dan Kelayakan Finansial Minuman Bubuk Herbal Bawang Berlian (Eleutherine americana Merr). Jurnal REKAYASA DAN MANAJEMEN AGROINDUSTRI Vol 5 (2) : 67-76.

Karjono. 2017. Analisis Titik Impas Untuk Menciptakan Efisiensi Produksi Usaha Tani Melon di Kecamatan Praya Timur Kabupaten Lombok Tengah. Jurnal Agrotek Ummat Vol. 4 No. 2 : 67-72.

Najmudin. 2012. Teknik Peramalan Bisnis dengan Aplikasi Minitab. Universitas Jenderal Soedirman. Purwokerto

Nazir. 2003. Metode Penelitian. Ghalia Indonesia. Jakarta.

Rischkowsky, B. 2017. Update on the sheep and goat meat value chain transformation in Ethiopia. Paper pada workshop on developing intervention packages for small ruminant value chain target sites, Addis Ababa, 19-20 April 2017.

Sodiq, A. 2010. Pola Usaha Peternakan Kambing dan Kinerja Produktivitasnya di Wilayah Eks-Karesidenan Banyumas Jawa Tengah. Jurnal Agripet : Vol (10) No.2, 2010. 